\title{
Influence of fluoride-containing adhesives and bleaching agents on enamel bond strength
}

\author{
Vanessa Cavalli(a) \\ Priscila Cristiane Suzy Liporoni ${ }^{(a)}$ \\ Marcos Augusto do Rego(a) \\ Sandrine Bittencourt Berger ${ }^{(b)}$ \\ Marcelo Giannini(c) \\ (a) Department of Restorative Dentistry, School \\ of Dentistry, Univ de Taubaté - UNITAU, \\ Taubaté, SP, Brazil. \\ (b) Department of Restorative Dentistry, School \\ of Dentistry, Univ Norte do Paraná - \\ UNOPAR, Londrina, PR, Brazil. \\ (c) Department of Restorative Dentistry, \\ Piracicaba Dental School, Univ Estadual de \\ Campinas - Unicamp, Piracicaba, SP, Brazil.
}

Declaration of Interests: The authors certify that they have no commercial or associative interest that represents a conflict of interest in connection with the manuscript.

Corresponding Author:

Vanessa Cavalli

E-mail:vcavalli@yahoo.com

Submitted: May 21, 2012

Accepted for publication: Aug 17, 2012

Last revision: Sep 03, 2012

\begin{abstract}
This study evaluated the influence of fluoride-containing carbamide peroxide (CP) bleaching agents and adhesive systems on bonded enamel interfaces that are part of the dynamic $\mathrm{pH}$ cycling and thermal cycling models. The buccal surfaces of 60 bovine incisors were restored with a composite resin and bonded with three- and two-step, etch-and-rinse, fluoride-containing adhesives, Optibond FL (FL) and Optibond Solo Plus (SP), respectively. Restored teeth were subjected to thermal cycling to age the interface. Both SP and FL adhesive-restored teeth were bleached $(\mathrm{n}=10)$ with $10 \% \mathrm{CP}(\mathrm{CP})$ and $10 \% \mathrm{CP}+$ fluoride (CPF) or were left unbleached (control). Bleaching was performed for 14 days simultaneously with $\mathrm{pH}$ cycling, which comprised of $14 \mathrm{~h}$ of remineralization, $2 \mathrm{~h}$ of demineralization and $8 \mathrm{~h}$ of bleaching. The control groups (FL and SP) were stored in remineralizing solution during their bleaching periods and were also subjected to carious lesion formation. Parallelepiped-shaped samples were obtained from the bonded interface for microtensile bond strength ( $\mu \mathrm{TBS}$ ) testing. The enamel $\mu \mathrm{TBS}$ of the FL and SP groups (control, not bleached) were higher $(\mathrm{p}<0.05)$ than those of the bleached interfaces $(\mathrm{FL}>\mathrm{FL}+\mathrm{CPF}=\mathrm{FL}+\mathrm{CP}$ and $\mathrm{SP}>\mathrm{SP}+\mathrm{CPF}=\mathrm{SP}+\mathrm{CP})$. The groups subjected to treatment with the fluoride-containing bleaching agents exhibited similar $\mu \mathrm{TBS}$ compared to regular bleaching agents. Bleaching agents, regardless of whether they contained fluoride, decreased enamel bond strength.
\end{abstract}

Descriptors: Bleaching Agents; Fluorides; Dental Enamel; Tooth Remineralization.

\section{Introduction}

The durability of an adhesive restoration is related to the integrity of the enamel/dentin interface. Marginal gaps in the restoration frequently lead to post-operative sensibility, marginal staining, and the development of pulp pathologies as a consequence of secondary carious lesions. ${ }^{1}$ The development of secondary caries is similar to that of primary caries but differs according to the location and characteristics of the surface, such as roughness and marginal defects. ${ }^{2,3}$

Conventional three- and two-step etch-and-rinse adhesives can effectively seal the enamel interface. ${ }^{4}$ To prevent caries around the interface, fluoride has been added to some of these adhesives, thus allowing these agents to work as "fluoride reservoirs" to avoid mineral loss by inhibiting 
demineralization and enhancing remineralization. ${ }^{5}$ However, the ability of adhesives to release fluoride at the interface has been evaluated under caries challenge conditions, ${ }^{6-8}$ so it is uncertain whether the amount of fluoride released at the restoration wall may be able to prevent or reverse the development of caries. ${ }^{8}$

In clinical situations, the adhesive interface is subjected not only to caries challenges but also to agents that compromise marginal integrity. Among these, carbamide peroxide bleaching emerges as a common esthetic procedure; however, several reports demonstrate its potential adverse effects on the enamel, ${ }^{9,10}$ particularly at the enamel-bonded interface. ${ }^{11}$ The side effects of peroxides on enamel include increased enamel porosity, pitting, erosion, demineralization of the periphery of enamel prisms and mineral loss promoted by the decrease in the inorganic content. ${ }^{9-12}$ To reverse the undesirable effects of bleaching, sodium fluoride has been added to some of these agents. ${ }^{13,14}$ Fluoride-containing bleaching agents may generate fluoridated hydroxyapatite and calcium fluoride crystals on the enamel, which may accelerate the remineralization of the bleached enamel. ${ }^{15}$

To date, no study has reported the effects of fluoride-containing bleaching agents at the interface of three- and two-step fluoride-containing adhesive restorations. Therefore, this study aimed to evaluate the bond strength of the adhesive/enamel interface subjected to $10 \%$ carbamide peroxide $(\mathrm{CP})$ agents with and without fluoride $\left(\mathrm{F}^{-}\right)$using a dynamic $\mathrm{pH}$ cycling model. ${ }^{16}$ The null hypotheses tested were that under caries challenge conditions, (1) no differences will be observed in enamel bond strengths between bleaching agents, with and without $\mathrm{F}^{-}$, and (2) no differences will be noted between the threeand two-step etch-and-rinse fluoride-containing adhesives.

\section{Methodology \\ Experimental design}

Sixty bovine incisors were obtained after approval of the Ethical Research Committee of Taubaté Dental School (protocol \#0033/07), Unitau, Brazil, and randomly divided into six groups $(n=10)$ ac- cording to the following factors:

1. adhesive systems: Optibond FL (FL) and Optibond Solo Plus (SP) (three- and two-step, etchand-rinse adhesives, respectively, Kerr, Danbury, USA) and

2. bleaching treatment: without bleaching, bleaching with $10 \% \mathrm{CP}(\mathrm{CP})$ or $10 \% \mathrm{CP}$ with $\mathrm{F}^{-}(\mathrm{CPF})$ (Opalescence, Ultradent Products, South Jordan, USA).

The factors and levels were arranged as follows:

1. (FL): Optibond FL without bleaching - control

2. $(\mathrm{FL}+\mathrm{CPF})$ : Optibond FL and $10 \% \mathrm{CP}$ bleaching with $\mathrm{F}^{-}$

3. $(\mathrm{FL}+\mathrm{CP})$ : Optibond FL and $10 \% \mathrm{CP}$ bleaching without $\mathrm{F}^{-}$

4. (SP): Optibond SP without bleaching - control

5. $(\mathrm{SP}+\mathrm{CPF})$ : Optibond SP and $10 \%$ CP bleaching with $\mathrm{F}^{-}$

6. $(\mathrm{SP}+\mathrm{CP})$ : Optibond SP and $10 \% \mathrm{CP}$ bleaching without $\mathrm{F}^{-}$

Treatment consisted of bonding with FL or SP and bleaching treatment associated with a $\mathrm{pH}$ cycling model. After treatment, enamel bonding was evaluated by means of the $\mu \mathrm{TBS}$, and the interface was analyzed based on the fracture failure modes. Table 1 summarizes the materials tested.

\section{Sample preparation}

The incisors were cleaned and stored in thymol solution at $5^{\circ} \mathrm{C}$ for 2 weeks and stored in deionized water for $24 \mathrm{~h}$ before beginning the experiment. The roots were removed and standard class I cavities ( $4 \times 7 \mathrm{~mm}$ and $3 \mathrm{~mm}$ deep) were prepared on the buccal surface with diamond burs (FG 57 - KG Sorensen, Barueri, Brazil). The preparations were incrementally restored with a hybrid composite resin (Point 4, Kerr, Danbury, USA) after bonding with one of the two test adhesive systems (FL and SP) according to the manufacturers' directions.

\section{Thermal cycling}

Samples of all groups were subjected to 2,000 thermal cycles $^{17}$ (MSCT-3 PLUS - Marcelo NucciME, São Carlos, Brazil) in deionized water baths 
Table 1 -Test materials, batch numbers and composition.

\begin{tabular}{l|l|l}
\hline $\begin{array}{l}\text { Product, manufacturer and } \\
\text { batch number }\end{array}$ & \multicolumn{2}{l}{ Composition } \\
\hline $\begin{array}{l}\text { Optibond Solo Plus* } \\
\text { (2880449) }\end{array}$ & $\begin{array}{l}\text { Bis-GMA, HEMA, GDM, } \\
\text { GPDM, CQ, water }\end{array}$ & $\begin{array}{l}\text { Filler: barium aluminoborosilicate } \\
\text { glass, silicon dioxide, sodium } \\
\text { hexafluorosilicate (filled 15\% by wt) }\end{array}$ \\
\hline $\begin{array}{l}\text { Optibond FL* } \\
\text { (2850809) }\end{array}$ & $\begin{array}{l}\text { Primer: HEMA, GPDM, } \\
\text { PAMM, ethanol, water, CQ } \\
\text { Adhesive: Bis-GMA, HEMA, } \\
\text { GPDM, CQ, glycerol, } \\
\text { dimethacrylate resins }\end{array}$ & $\begin{array}{l}\text { Filler: barium aluminoborosilicate } \\
\text { glass, silicon dioxide, sodium } \\
\text { hexafluorosilicate (filled 48\% by wt) }\end{array}$ \\
\hline $\begin{array}{l}\text { Point 4* } \\
\text { (2927957) }\end{array}$ & $\begin{array}{l}\text { Resin: Bis-GMA, EGDMA } \\
\text { and Bis-EMA }\end{array}$ & $\begin{array}{l}\text { Filler: barium glass and silica } \\
\text { (filled 76\% by wt) }\end{array}$ \\
\hline $\begin{array}{l}\text { Opalescence 10\% Regular** } \\
\text { (B2LCV) }\end{array}$ & $\begin{array}{l}\text { carbamide peroxide, } \\
\text { glycerin, carbopol, deionized water, potassium hydroxide }\end{array}$ \\
\hline $\begin{array}{l}\text { Opalescence 10\% PF** } \\
\text { (B2CQ8) }\end{array}$ & $\begin{array}{l}\text { carbamide peroxide, sodium fluoride, } \\
\text { glycerin, carbopol, deionized water, potassium nitrate }\end{array}$ \\
\hline
\end{tabular}

*Kerr, Danbury, USA; **Ultradent Products, South Jordan, USA. Abbreviations: Bis-GMA = bisphenol A glycidyl dimethacrylate; HEMA = 2-hydroxyethyl methacrylate; GDM = glycerol dimethacrylate; GPDM = glycerophosphate-dimethacrylate; $C Q=$ camphorquinone; $P A M M=$ phthalic acid monomethacrylate; Bis-EMA = ethoxylated bisphenol A glycol dimethacrylate; EGDMA = ethylene glycol dimethacrylate. at $5-55^{\circ} \mathrm{C} \pm 1^{\circ} \mathrm{C}$ to age the bonded interface. After the thermal cycles, a nail varnish was applied $2 \mathrm{~mm}$ away from and around the bonded interface, leaving a standardized area for initial carious lesions. The samples were stored for $24 \mathrm{~h}$ in remineralizing solution before the caries regimen and bleaching treatment.

\section{Chemical caries regimen and bleaching treatment}

The cycle consisted of the application of the bleaching agent for $8 \mathrm{~h},{ }^{11}$ followed by fluoridated dentifrice immersion ( $1 \mathrm{~g}$ of dentifrice: $3 \mathrm{ml}$ of water) for $1 \mathrm{~min}$, demineralization for $2 \mathrm{~h}(0.05 \mathrm{M}$ acetate buffer, $2.2 \mathrm{mM} \mathrm{CaCl}_{2}, 2.2 \mathrm{mM} \mathrm{Na}_{3} \mathrm{PO}_{4}, 1 \mathrm{ppm}$ $\mathrm{NaF}, \mathrm{pH} 4.5$, and $6.25 \mathrm{~mL} / \mathrm{mm}^{2}$ of enamel $)^{16}$ and a second fluoridated dentifrice immersion for $1 \mathrm{~min}$. Samples of all groups were then immersed overnight in remineralizing solution $\left(1.5 \mathrm{mM} \mathrm{CaCl}_{2}, 0.9 \mathrm{mM}\right.$ $\mathrm{Na}_{3} \mathrm{PO}_{4}, 0.15 \mathrm{M} \mathrm{KCL}, \mathrm{pH} 7.0,3.125 \mathrm{~mL} / \mathrm{mm}^{2}$ of enamel ${ }^{16}$ with the cycle continuing on the following day. This procedure was carried out for 14 days, corresponding to an average duration of homeapplied bleaching treatment. The control groups (SP and FL, not subjected to bleaching) were kept in the remineralizing solution while bleaching was performed for the other groups. The bleaching agent was applied on the enamel surface $(0.05 \mathrm{~g})$, and the samples were stored at $37^{\circ} \mathrm{C}$ during bleaching, remineralization and demineralization. After bleaching, the specimens were rinsed thoroughly with deionized water and kept for $24 \mathrm{~h}$ in water prior to mechanical evaluation.

\section{Microtensile bond strength ( $\mu \mathrm{TBS}$ ) testing}

The palatal surfaces of the restored teeth were polished in a grinding machine to reduce the thickness of the incisors to $1 \mathrm{~mm}$-thick blocks. The block was sectioned longitudinally by dividing the teeth into two hemi-sections that were serially cut (mesial to distal) in a cutting machine (1100 Isomet, Buheler Ltd., Lake Bluff, USA). Cutting was performed in a direction perpendicular to the bonded interface to produce parallelepiped-shaped samples ("sticks") with a thickness of $0.8 \mathrm{~mm}$. This procedure yielded approximately three sticks per tooth, and no premature debonding occurred during sample preparation. The sticks were fixed to the Bencor device and subjected to a $\mu$ TBS testing in a universal testing machine (4411, Instron Co., Canton, USA) at $0.5 \mathrm{~mm} / \mathrm{min}$ crosshead speed until failure.

\section{Failure mode}

The debonded enamel sites were viewed under a stereoscopic loupe at $40 \times$ magnification to assess the failure mode. Failure was classified as adhesive 


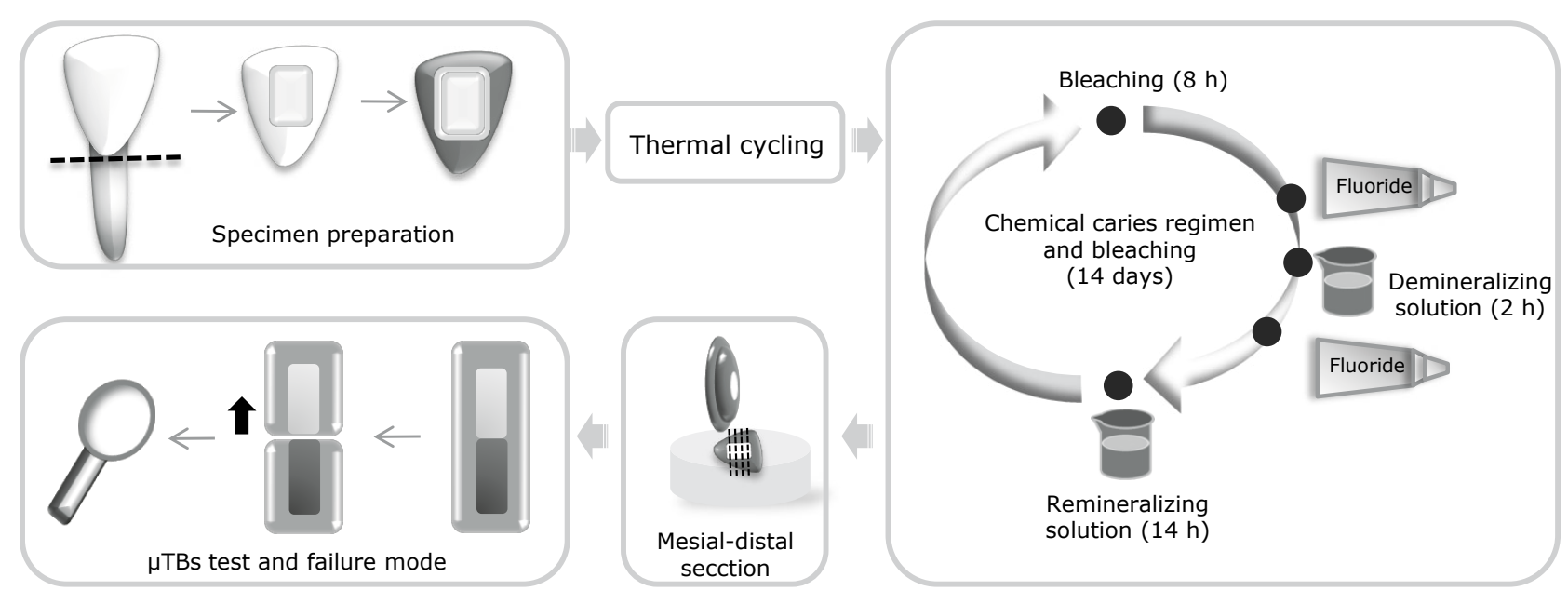

Figure 1 - Schematic illustration of the methodology.

(up to $90 \%$ of enamel surface exposure), cohesive in enamel, cohesive in resin or mixed failure (also nominated adhesive and cohesive failure indicating up to $50 \%$ of the enamel surface covered with adhesive or resin). Figure 1 shows a schematic illustration of the methodology.

\section{Statistical analysis}

Effects of the dependable variables, adhesive systems $(\mathrm{p}=0.0016)$ and treatments $(\mathrm{CP}$ with and without $\mathrm{F}$ and no bleaching, $\mathrm{p}=0.0022$ ) and the interactions (adhesives $\times$ treatments, $\mathrm{p}=0=0019$ ) with enamel were analyzed. The normal distribution of the $\mu$ TBS test values was verified by using Kolmogorov-Smirnov and Lilliefors tests $(p>0.05)$, and a parametric two-way ANOVA and Tukey test were performed. A value of $5 \%$ was considered significant (SAS 9.0 software, SAS Institute, Cary, USA).

\section{Results}

\section{Microtensile bond strength ( $\mu$ TBS) testing}

The results of the $\mu$ TBS test (Table 2) indicated that the bond strength of the control group bonded with FL was higher than that of the enamel bonded with SP $(p=0.0016)$. However, both groups presented with higher $\mu$ TBS values compared to the bleached groups (CPF and CP, $\mathrm{p}<0.0001$ ). No differences were observed in enamel bond strength between the groups subjected to CP $10 \%$
Table 2 - Enamel bond strength after treatment with various adhesives and bleaching agents.

\begin{tabular}{c|r|r|c|c|c|r|c|c}
\hline Groups & \multicolumn{3}{|c|}{$\mathrm{FL}$} & $\mathrm{n}$ & \multicolumn{3}{c|}{ SP } & $\mathrm{n}^{*}$ \\
\hline Control & 53.94 & $(12.84)$ & $\mathrm{Aa}$ & 27 & 42.23 & $(10.84)$ & $\mathrm{Ab}$ & 31 \\
\hline CPF & 34.01 & $(9.27)$ & $\mathrm{Ba}$ & 32 & 31.26 & $(5.08)$ & $\mathrm{Ba}$ & 30 \\
\hline $\mathrm{CP}$ & 34.32 & $(8.65)$ & $\mathrm{Ba}$ & 25 & 34.22 & $(7.38)$ & $\mathrm{Ba}$ & 28 \\
\hline
\end{tabular}

Means and standard deviations ( $\mathrm{MPa}$ ) followed by different letters are different at $p<0.05$, according to ANOVA and Tukey's tests (capital letters - columns; lower case letters - lines). ${ }^{*}$ Number of samples per group.

$(\mathrm{FL}+\mathrm{CPF}=\mathrm{F}+\mathrm{CP}$ and $\mathrm{SP}+\mathrm{CP}=\mathrm{SP}+\mathrm{CPF})$, regardless of the addition of $\mathrm{F}$ to the bleaching agents $(\mathrm{p}>0.05)$.

\section{Failure modes}

A total of 45 to $50 \%$ of the failure modes in the control groups (FL and SP, respectively) were of the adhesive type. The bleached enamel interfaces exhibited mostly cohesive fractures in the enamel, corresponding to 35 to $45 \%$ of the total failure pattern (Figure 2).

\section{Discussion}

Secondary caries development along the margins of an existing restoration is considered a major cause for the replacement of restorations over time. ${ }^{2,3}$ Therefore, controlling and/or preventing this condition is a concern that has led to the development of adhesives with anticariogenic potential. ${ }^{5}$ However, aside from biofilm formation, the interface of ex- 
Figure 2 - Failure modes of the debonded specimens expressed as percent values (\%).

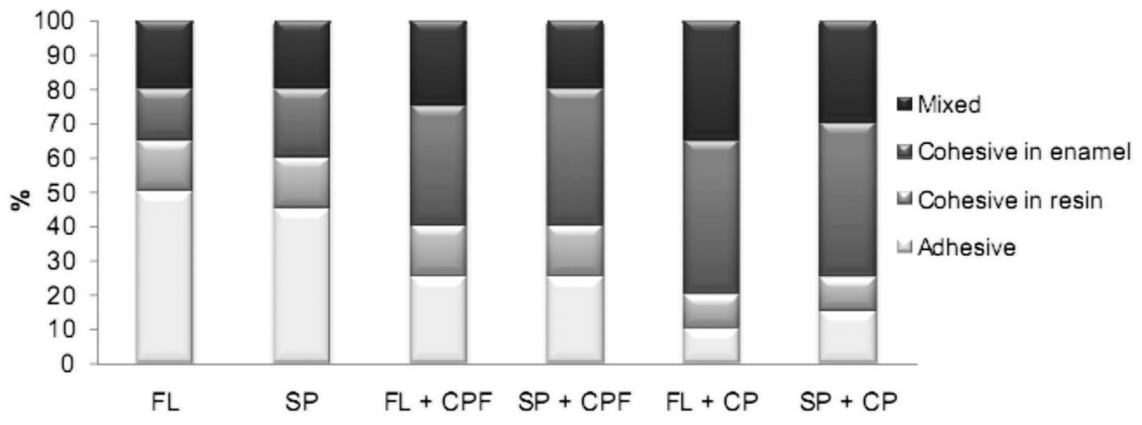

reported values were recovered after 7 and 14 days of storage. According to the authors, the positive outcome of $\mathrm{F}^{-}$addition to bleaching agents may assist subsequent restorative treatment by inhibiting enamel demineralization. ${ }^{21}$

Failure mode patterns of $\mathrm{CP}$-treated interfaces demonstrated predominance ( 35 to $45 \%$ ) of cohesive failure in the enamel for both the bleaching agents used in this study. The cohesive failures confirm the hypothesis that bleaching may promote enamel structural changes, thus initializing fracture during debonding at the enamel rather than at the adhesive-bonded interface. Cavalli et al. ${ }^{12}$ observed that bleached fractured enamel presented altered prism structure following exposure to regular (fluoride-free) carbamide peroxides. Scanning electron microscopy showed a preference for dissolution of the boundaries between the prism and the interprismatic substance and a porous-like appearance of the bleached prisms. The porosity created by the bleaching agent in the enamel may have acted as a stress raiser during $\mu \mathrm{TBS}$ testing, resulting in premature failures. ${ }^{12}$

The control groups (FL and SP), however, exhibited both higher bond strengths than bleached enamel and a predominance of adhesive failure (45 to $50 \%$ ). Differences were observed between the three-step (FL) and two-step (SP) etch-and-rinse adhesives ( $\mu$ TBS FL $>\mu$ TBS SP). Three- and twostep conventional etch-and-rinse adhesive systems were chosen because these agents could effectively seal the interface and promote reliable adhesion to enamel. Acid-etching selectively dissolves hydroxyapatite crystals and creates enamel microporosities, which are infiltrated by monomers that form resin tags and promote micromechanical retention. ${ }^{4}$ The 
etch-and-rinse adhesives involve a separate etching step, but the two-step combines the primer and the adhesive resin into one solution. ${ }^{4}$ In a clinical trial studying adhesives (two self-etching and two etch-and-rinse), Perdigão et al. observed that, after 18 months, enamel marginal deficiencies were less prevalent in teeth bonded with etch-and-rinse systems compared to teeth bonded with self-etching adhesives. ${ }^{22}$ The authors also note that the threestep etch-and-rinse have better laboratory and clinical performance than the two-step adhesives; in the case of the former, the application of the hydrophilic monomer is performed separately before the application of the hydrophobic monomer, granting optimal resin infiltration and mechanical interlocking. ${ }^{22}$

Peris et al. ${ }^{8}$ evaluated the $\mu$ TBS of a dentin interface bonded with fluoride-containing and fluoridefree adhesives and subjected (or not) to $\mathrm{pH}$ cycling. They observed that $\mathrm{pH}$ cycling reduced dentin bond strength of all adhesives. The authors attribute the decreased $\mu$ TBS values to the resulting demineralization occurring around the restorations to weaken the bonding, regardless of the presence of fluoride within the adhesives. ${ }^{8}$ In the current study, all groups were subjected to $\mathrm{pH}$ cycling, which caused demineralization to occur around the bonded interface, and the bleaching treatment of the enamel interface, which was performed simultaneously with the $\mathrm{pH}$ cycling, was able to decrease bond strength to enamel, regardless of the presence of $\mathrm{F}^{-}$in the

\section{References}

1. Dennison JB, Sarrett DC. Prediction and diagnosis of clinical outcomes affecting restoration margins. J Oral Rehabil. 2012 Apr;39(4):301-18.

2. Kidd EA. Diagnosis of secondary caries. J Dent Educ. 2001 Oct;65(10):997-1000.

3. Lima FG, Romano AR, Correa MB, Demarco FF. Influence of microleakage, surface roughness and biofilm control on secondary caries formation around composite resin restorations: an in situ evaluation. J Appl Oral Sci. 2009 Jan-Feb;17(1):61-5.

4. Van Meerbeek B, De Munck J, Yoshid Y, Inoue S, Vargas M, Vijay P, et al. Buonocore memorial lecture. Adhesion to enamel and dentin: current status and future challenges. Oper Dent. 2003 May-Jun;28(3):215-35. bleaching agents. Possibly, if the amounts of $\mathrm{F}^{-}$released from the bleaching agents were sufficient to remineralize the enamel, then the bond strengths exhibited by groups treated with bleaching gels containing $\mathrm{F}^{-}(\mathrm{FL}+\mathrm{CPF}$ and $\mathrm{SP}+\mathrm{CPF})$ would be similar to the bond strengths of the non-bleached groups (FL and SP). These results should, however, be confirmed with an in situ evaluation to corroborate the findings of this preliminary in vitro report.

Our first null hypothesis tested was accepted as, under caries challenge, (1) no differences were observed in the enamel bond strength after treatment with the bleaching agents, either with or without $\mathrm{F}^{-}$. The second hypothesis was rejected because (2) differences were observed between the three- and twostep fluoride-containing adhesive systems.

\section{Conclusion}

Bleaching treatment decreased the enamel bond strengths of existing adhesive restorations, regardless of the addition of fluoride to these agents. In addition, the three-step adhesive displayed higher bond strength values than the simplified two-step etch-and-rinse adhesive.

\section{Acknowledgments}

This investigation was supported by grants 07/53878-2, 09/01228-0 and 09/01060-1 from the State of São Paulo Research Foundation, FAPESP, São Paulo, Brazil.
5. Silva BMCG, França FMG, Flório FM, Basting RT. In situ anticariogenic effect of adhesive systems containing fluoride and MDPB. Am J Dent. 2010 Apr;23(2):75-80.

6. Hara AT, Queiroz CS, Freitas PM, Giannini M, Serra MC, Cury JA. Fluoride release and secondary caries inhibition by adhesive systems on root dentine. Eur J Oral Sci 2005 Jun;113(3):245-50.

7. Lobo MM, Gonçalves RB, Ambrosano GMB, Pimenta LAF. Chemical or microbiological models of secondary caries development around different dental restorative materials. J Biomed Mater Res B Appl Biomater. 2005 Aug;74(2):725-31.

8. Peris AR, Mitsui FH, Lobo MM, Bedran-Russo AK, Marchi GM. Adhesive systems and secondary caries formation: Assessment of dentin bond strength, caries lesions depth and fluoride release. Dent Mater. 2007 Mar;23(3):308-16. 
9. Basting RT, Rodrigues AL, Serra MC. Micromorphology and surface roughness of sound and demineralized enamel and dentin bleached with a $10 \%$ carbamide peroxide bleaching agent. Am J Dent. 2007 Apr;20(2):97-102.

10. Pinto CF, Paes Leme AF, Cavalli V, Giannini M. Effect of $10 \%$ carbamide peroxide bleaching on sound and artificial enamel carious lesions. Braz Dent. J 2009;20(1):48-53.

11. Silva AP, Oliveira R, Cavalli V, Arrais CA, Giannini M, Carvalho RM. Effect of peroxide-based bleaching agents on enamel ultimate tensile strength. Oper Dent. 2005 May-Jun;30 (3):318-24.

12. Cavalli V, Giannini M, Carvalho RM. Effect of carbamide peroxide bleaching agents on tensile strength of human enamel. Dent Mater. 2004 Oct;20(8):733-39.

13. Cavalli V, Rodrigues LK, Paes-Leme AF, Soares LE, Martin AA, Berger SB, et al. Effects of the addition of fluoride and calcium to low-concentrated carbamide peroxide agents on the enamel surface and subsurface. Photomed Laser Surg. 2011 May;29(5):319-25.

14. Cavalli V, Rodrigues LK, Paes-Leme AF, Brancalion ML, Arruda MA, Berger SB, et al. Effects of bleaching agents containing fluoride and calcium on human enamel. Quintessence Int. 2010 Sep;41(8):e157-65.

15. Tanizawa Y. Reaction characteristics of a tooth-bleaching agent containing $\mathrm{H}_{2} \mathrm{O}_{2}$ and $\mathrm{NaF}$ : in vitro study of crystal structure change in treated hydroxyapatite and chemical states of incorporated fluoride. J Cosmet Sci. 2005 MarApr;56(2):121-34.

16. Shinkai RS, Cury AA, Cury JA. In vitro evaluation of secondary caries development in enamel and root dentin around luted metallic restoration. Oper Dent. 2001 Jan-Feb;26(1):52-9.

17. Gale MS, Darvell BW. Thermal cycling procedures for laboratory testing for dental restorations. J Dent. 1999 Fev;27(2):89-99.

18. Maia E, Baratieri LN, Andrada MAC, Monteiro Jr S, Vieira LC. The influence of two home-applied bleaching agents on enamel microhardness: an in situ study. J Dent. 2008 Jan;36(1):2-7.

19. Al-Qunaian TA. The effect of whitening agents on caries susceptibility of human enamel. Oper Dent. 2005 MarApr;30(2):265-70.

20. Tschoppe P, Neumann K, Mueller J, Kielbassa AM. Effect of fluoridated bleaching gels on the remineralization of predemineralized bovine enamel in vitro. J Dent. 2009 Fev;37(2):156-62.

21. Chuang SF, Chen HP, Chang CH, Liu JK. Effect of fluoridated carbamide peroxide gels on enamel microtensile bond strength. Eur J Oral Sci. 2009 Aug;117(4):435-41.

22. Perdigão J, Dutra-Corrêa M, Saraceni CH, Ciaramicoli MT, Kiyan BH, Queiroz CS. Randomized clinical trial of four adhesion strategies: 18-month results. Oper Dent. 2012 JanFev;37(1):3-11. 